\title{
High Photosensitivity in Cis-Poly(phenylacetylene) Films Irradiated by Electron Beams
}

\author{
Jian ZhaO, ${ }^{*}$ Mujie YANG, and Zhiquan SHEN \\ Chemistry Department, Zhejiang University, \\ Hangzhou 310027, P.R. China
}

(Received September 7, 1990)

\begin{abstract}
Photosensitivity in cis-poly(phenylacetylene) (cis-PPA) films prepared with rare-earth coordination catalysts can be greatly improved by the irradiation with electron beams. Irradiation energy is a key factor for obtaining high photosensitivity. The potential discharge rate and difference between the initial and residual potential under an IR-lamp exposure increase with increasing energy from 1.3 to $1.8 \mathrm{MeV}$. Photosensitivity in cis-PPA remains almost constant if the irradiation flux is more than the critical flux $\left(1 \times 10 \mathrm{ecm}^{-1}\right)$. The irradiation effect for electron beams is strongly dependent on the microstructure of PPA and irradiation atmosphere. The dependence of the photosensitivity of the irradiated cis-PPA films on their storage time and temperature has been investigated. The characterization results of the irradiated cis-PPA have been described. A mechanism by which electron beams induce high photosensitivity in cis-PPA is proposed.
\end{abstract} KEY WORDS Cis-Polyphenylacetylene Films / Photosensitivity / Electron
Beam Irradiation /

Polyphenylacetylene (PPA) is a conjugated polymer which has significant semiconductor and photoconductor properties upon doping with electron acceptors or sensitizing with dyes. ${ }^{1-3}$ Our recent paper presented a novel technique to convert cis-PPA films prepared with rare-earth coordination catalysts to a highly photosensitive material by irradiation with ${ }^{60} \mathrm{Co}-\gamma$ rays. ${ }^{4}$ This paper reports further work on the photosensitivity in cis-PPA films irradiated by electron beams in order to systematically understand the irradiation effect. The dependence of the photosensitivity in rare-earth PPA films on irradiation energy and flux, configuration of PPA films and an irradiation atmosphere have been investigated by means of a potential discharge technique. The change in photosensitivity of irradiated cis-PPA with storage time and temperature have been observed. A mechanism by which high photosensitivity in cis-PPA is induced by electron beam irradiation is proposed.

\section{EXPERIMENTAL}

\section{Preparation of PPA Films}

The cis-PPA films used in this research were prepared by a direct method of polymerization of phenylacetylene into PPA films with rare-earth coordination catalysts in a hexane/ toluene mixed solvent at $30^{\circ} \mathrm{C}^{5-6}$ The ciscontent of PPA obtained was more than $90 \%$. The trans-PPA was obtained by thermal isomerization of cis-PPA in a nitrogen atmosphere at $190^{\circ} \mathrm{C}$ for more than half an hour. The number average molecular weights of the cis-PPA and trans-PPA were about $10^{5}$ and $10^{4}$, respectively, as measured by GPC referenced with polystyrene standard samples.

\footnotetext{
* Now is working in Guangzhou Institute of Chemistry, Academia Sinica, Guangzhou 510650, P.R. China.
} 
Preparation of Highly Photosensitive Samples

The cis- or trans-PPA films pre-compressed under $600 \mathrm{~kg} \mathrm{~cm}^{-2}$ (thickness: $70-100 \mu \mathrm{m}$ ) were exposed to electron beam irradiation at room temperature in air.

\section{Measurement}

The technique used in photosensitivity studies employs the photo-induced discharge of a corona-charged sample under a $250 \mathrm{~W}$ IR-lamp. ${ }^{4}$ Other characterization methods and instrument for PPA are given in detail in our previous paper. ${ }^{6-7}$

\section{RESULTS AND DISCUSSION}

\section{Photosensitivity}

Photosensitivity in cis-PPA films irradiated

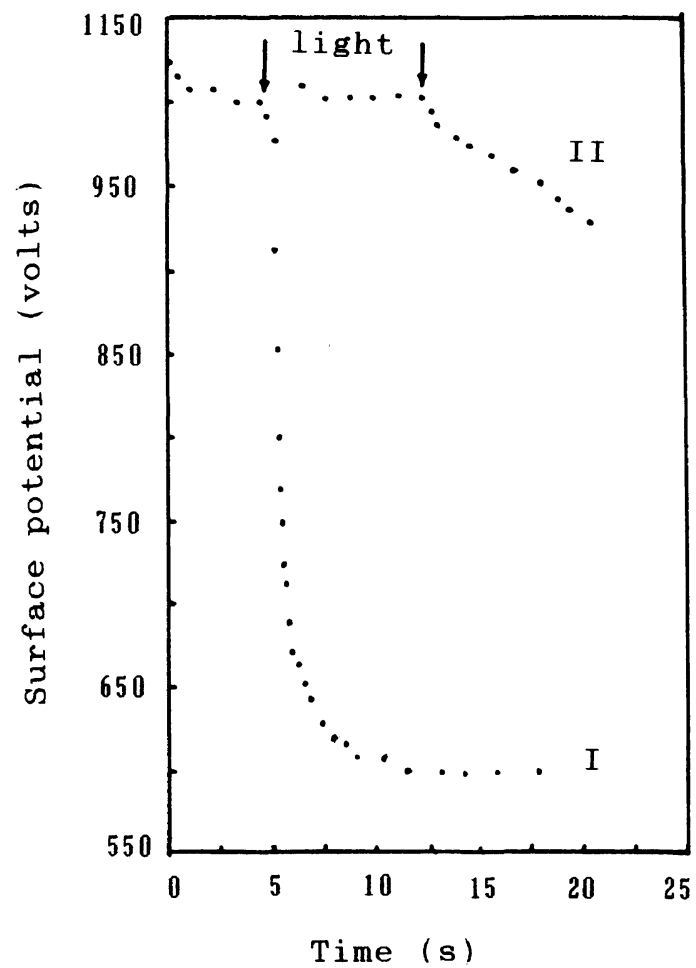

Figure 1. Typical photoinduced discharge curves (PIDC) for negatively charged samples. I: Electron beam irradiated cis-PPA (Irradiation conditions: irradiation energy, $1.8 \mathrm{MeV}$; Irradiation flux, $3 \times 10^{15} \mathrm{e} \mathrm{cm}^{-2}$; irradiation rate, $1.2 \times 10^{12} \mathrm{e} \mathrm{s}^{-1} \mathrm{~cm}^{-2}$; in air). II: Unirradiated cis-PPA film. by electron beams has been investigated by means of a potential discharge technique. Figure 1 shows typical photoinduced discharge curves (PIDC) of negatively charged cis-PPA films under a $250 \mathrm{~W}$ IR-lamp exposure. During the dark period, the surface potential of irradiated (I) and unirradiated (II) cis-PPA films dropped very slowly as a function of time. However during the light period, the surface potential of (I) dropped very rapidly, and its maximum surface potential discharge rate was $893 \mathrm{~V} \mathrm{~s}^{-1}$, This being much higher than that of (II) $\left(84 \mathrm{~V} \mathrm{~s}^{-1}\right)$. Furthermore, the irradiated cis-PPA shows fast light responce and its residual surface potential after a short discharge remains almost constant. In a word, the photosensitivity in cis-PPA films was greatly improved after irradiation with electron beams. Compared to the photosensitivity in ${ }^{60} \mathrm{Co}-\gamma$ ray irradiated cis-PPA films, the electron beam irradiated films showed a higher surface potential discharge rate under an IR-lamp exposure. ${ }^{4}$

The dependence of the photosensitivity in electron beam irradiated cis-PPA films on irradiation energy and flux are summarized in Table I. It can be seen that the potential discharge rate $\left(\mathrm{Vs}^{-1}\right)$ and the difference between the initial and residual potentials (V) under an IR-lamp exposure increased with increasing irradiation energy from 1.3 to 1.8 MeV. This means that the photosensitivity in the electron beam irradiated cis-PPA films greatly improved under higher irradiation energy. It also can be seen from Table I that the critical irradiation flux required to make cis-PPA to produce a light response under an IR-lamp exposure was $1 \times 10^{15} \mathrm{e} \mathrm{cm}^{-2}$. Above this critical irradiation flux the potential discharge rate and difference for the irradiated cis-PPA remained constant with increasing irradiation flux from $2 \times 10^{15} \mathrm{ecm}^{-2}$ to $5 \times$ $10^{15} \mathrm{ecm}^{-2}$. The photosensitivity showed a slightly high value at $3 \times 10^{15} \mathrm{e} \mathrm{cm}^{-2}$. This is quite different from the effect of irradiation dose of ${ }^{60} \mathrm{Co}-\gamma$ rays on the photosensitivity 
Table I. Dependence of the potential discharge on the irradiation energy and the flux of electron beams

\begin{tabular}{|c|c|c|c|c|}
\hline \multirow{2}{*}{ Irraidation energy ${ }^{a}$} & Dark & Light $^{\mathrm{b}}$ & \multirow[b]{2}{*}{ Discharge percent } & \multirow[b]{2}{*}{ Photo-sensitivity } \\
\hline & \multirow{2}{*}{$\begin{array}{c}\text { Maximum rate of } \\
\text { discharge }\end{array}$} & \multirow{2}{*}{$\begin{array}{c}\text { Maximum rate of } \\
\text { discharge }\end{array}$} & & \\
\hline \multirow[t]{2}{*}{$\mathrm{MeV}$} & & & $\%$ & $1 s^{-1}$ \\
\hline & $\mathrm{Vs}^{-1}$ & $\mathrm{Vs}^{-1}$ & & \\
\hline 1.8 & 5.23 & 893 & 42.2 & 2.94 \\
\hline 1.5 & 5.10 & 670 & 50.7 & 2.46 \\
\hline 1.3 & 2.20 & 362 & 54.2 & 2.16 \\
\hline 0 & 1.60 & 84 & 8.7 & 0.25 \\
\hline \multicolumn{5}{|l|}{$\begin{array}{l}\text { Irradiation } \\
\text { flux } \mathrm{ecm}^{-2}\end{array}$} \\
\hline $5 \times 10^{15}$ & 0.60 & 362 & 65.7 & 1.70 \\
\hline $4 \times 10^{15}$ & 2.40 & 307 & 40.6 & 1.52 \\
\hline $3 \times 10^{15}$ & 2.20 & 362 & 54.2 & 2.16 \\
\hline $2 \times 10^{15}$ & 0.80 & 307 & 54.1 & 1.51 \\
\hline $1 \times 10^{15}$ & 2.70 & 167 & 23.7 & 0.82 \\
\hline 0 & 0.40 & 42 & 14.9 & 0.57 \\
\hline
\end{tabular}

a Irradiation of flux: $3 \times 10^{15} \mathrm{ecm}^{-2}$; Irradiation rate: $1.2 \times 10^{12} \mathrm{ecm}^{-2} \mathrm{~s}^{-1}$.

b Exposure under a $250 \mathrm{~W}$ IR-lamp; distance between the lamp and sample is just $100 \mathrm{~mm}$.

c Irradiation energy: $1.3 \mathrm{MeV}$; Irradiation rate; same as (a).

d Reciprocal of the time of exposure required to decrease the surface potential to one-half its initial value.

Table II. Dependence of time and temperature for storage of the irradiated PPA films on photosensitivity ${ }^{a}$

\begin{tabular}{|c|c|c|c|c|c|c|}
\hline \multirow{4}{*}{ No. } & \multirow{2}{*}{\multicolumn{2}{|c|}{$\begin{array}{c}\text { Temperature } \\
\text { of storage }\end{array}$}} & \multirow{2}{*}{$\begin{array}{l}\text { Time of } \\
\text { storage }\end{array}$} & \multirow{3}{*}{$\frac{\text { Dark }}{\begin{array}{c}\text { Maximum rate } \\
\text { of discharge }\end{array}}$} & \multirow{3}{*}{ 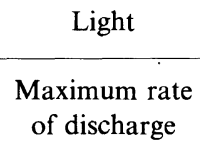 } & \multirow[b]{2}{*}{ Discharge } \\
\hline & & & & & & \\
\hline & \multirow{2}{*}{\multicolumn{2}{|c|}{${ }^{\circ} \mathrm{C}$}} & \multirow{2}{*}{$\mathrm{h}$} & & & $\%$ \\
\hline & & & & $\mathrm{Vs}^{-1}$ & $\mathrm{Vs}^{-1}$ & \\
\hline \multirow[t]{2}{*}{ I } & \multirow{2}{*}{\multicolumn{2}{|c|}{20}} & $<120$ & 5.23 & 893 & 42.2 \\
\hline & & & 1920 & 3.20 & 446 & 50.0 \\
\hline \multirow[t]{2}{*}{ II } & \multirow{2}{*}{\multicolumn{2}{|c|}{20}} & $<120$ & 0.6 & 362 & 65.7 \\
\hline & & & 1920 & 3.2 & 279 & 45.4 \\
\hline \multirow[t]{3}{*}{ III } & \multirow{2}{*}{\multicolumn{2}{|c|}{20}} & $<120$ & 3.7 & 302 & 60.2 \\
\hline & & & 480 & 3.7 & 298 & 59.6 \\
\hline & \multicolumn{2}{|c|}{$>50\left(\right.$ in $\left.\mathrm{N}_{2}\right)$} & 1 & 4.2 & 87 & 16.3 \\
\hline \multirow[t]{5}{*}{ a Conditions: } & \multirow[t]{2}{*}{ No. } & $\begin{array}{l}\text { Irradiation } \\
\text { energy }\end{array}$ & $\begin{array}{l}\text { Irradiation } \\
\quad \text { flux }\end{array}$ & $\begin{array}{l}\text { Irradiation } \\
\text { rate }\end{array}$ & & \\
\hline & & $\mathrm{MeV}$ & $\mathrm{ecm}^{-2}$ & $\mathrm{es}^{-1} \mathrm{~cm}^{-2}$ & & \\
\hline & I & 1.8 & $3 \times 10^{15}$ & $1.2 \times 10^{12}$ & & \\
\hline & II & 1.3 & $4 \times 10^{15}$ & $1.2 \times 10^{12}$ & & \\
\hline & III & 1.2 & $4 \times 10^{15}$ & $1.2 \times 10^{12}$ & & \\
\hline
\end{tabular}




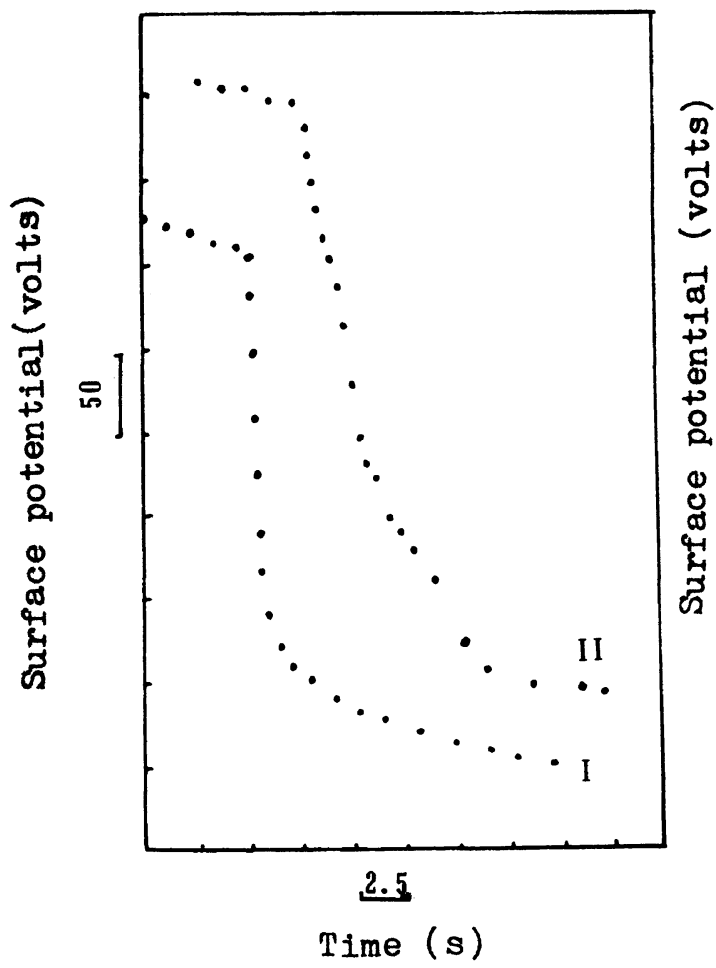

Figure 2. Potential discharge of cis(I) and trans(II) PPA films irradiated by electron beams Experimental conditions: irradiation energy, $1.0 \mathrm{MeV}$; others same as Figure 1.

improvement of cis-PPA. ${ }^{4}$ It appears that the irradiation energy is a key factor for obtaining high photosensitivity, and the irradiation flux plays little effect in the photosensitivity improvement if the irradiation flux is more than the critical value.

From the above results, it can be deduced that electron beam irradiation can convert cis-PPA films prepared with rare-earth coordination catalysts to a highly photosensitive material. The electron beam irradiation technique for inducing high photosensitivity of cis-PPA films is similar to the ${ }^{60} \mathrm{Co}-\gamma$ ray irradiation technique ${ }^{4}$ and completely different from the chemical methods reported in the literature. ${ }^{1-3}$

\section{Effects of Electron Beam Irradiation}

Our previous results indicated that the

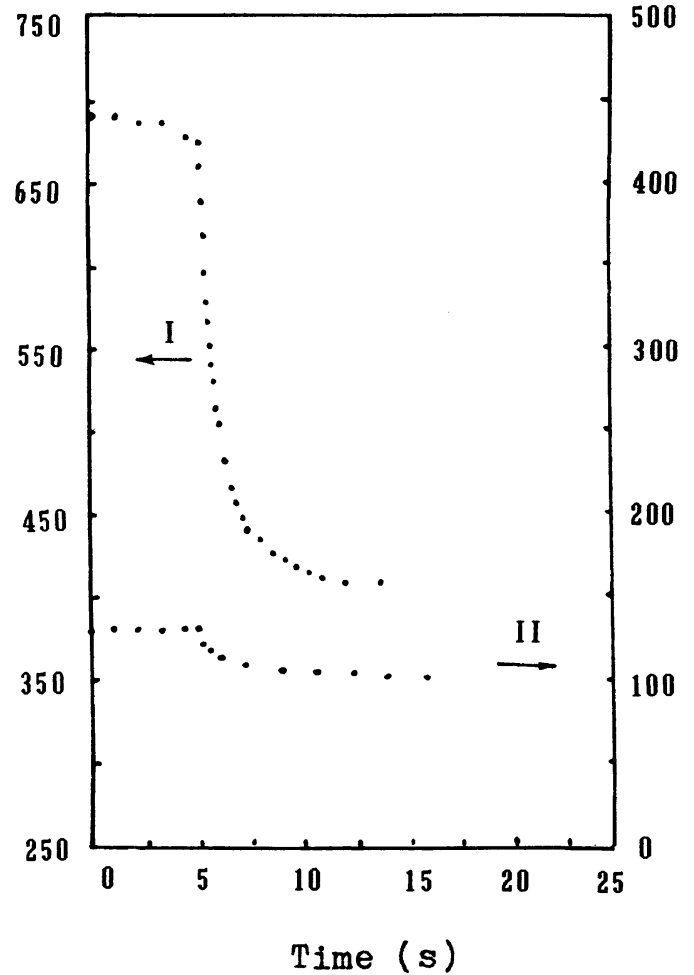

Figure 3. Potential discharge of cis-PPA irradiated by electron beams in air(I) and in a nitrogen (II) atmosphere. Experimental conditions: irradiation energy, $1.3 \mathrm{MeV}$; irradiation flux, $4 \times 10^{15} \mathrm{ecm}^{-2}$; others same as Figure 1 .

irradiation effect for ${ }^{60} \mathrm{Co}-\gamma$ rays was strongly dependent on the structure of PPA. Figure 2 reveals the different irradiation effects for electron beams between cis- and trans-PPA films. The photosensitivity of the electron beam irradiated cis-PPA was somewhat greater than that in the electron beam irradiated trans-PPA. It should be noted that ${ }^{60} \mathrm{Co}-\gamma$ ray irradiated trans-PPA has no noticeable irradiation effect ${ }^{4}$.

The influence of the irradiation atmosphere on photosensitivity of the cis-PPA films is shown in Figure 3. The photosensitivity of the cis-PPA irradiated with electron beams under a nitrogen atmosphere was the same as that of unirradiated cis-PPA. That is to say, there is no irradiation effect with electron beams in a nitrogen atmosphere for cis-PPA, and oxygen must play a role in the irradiation process.

In addition, methods for preparing the 
photosensitive samples have some influence on the photosensitivity in the electron beam irradiated cis-PPA films. Figure 4 shows the effect of the compression pressure on the photosensitivity. The photosensitivity in the electron beam irradiated original cis-PPA films not pre-compressed was not different from the unirradiated ones. Further, it can be seen that the photosensitivity in the electron beam

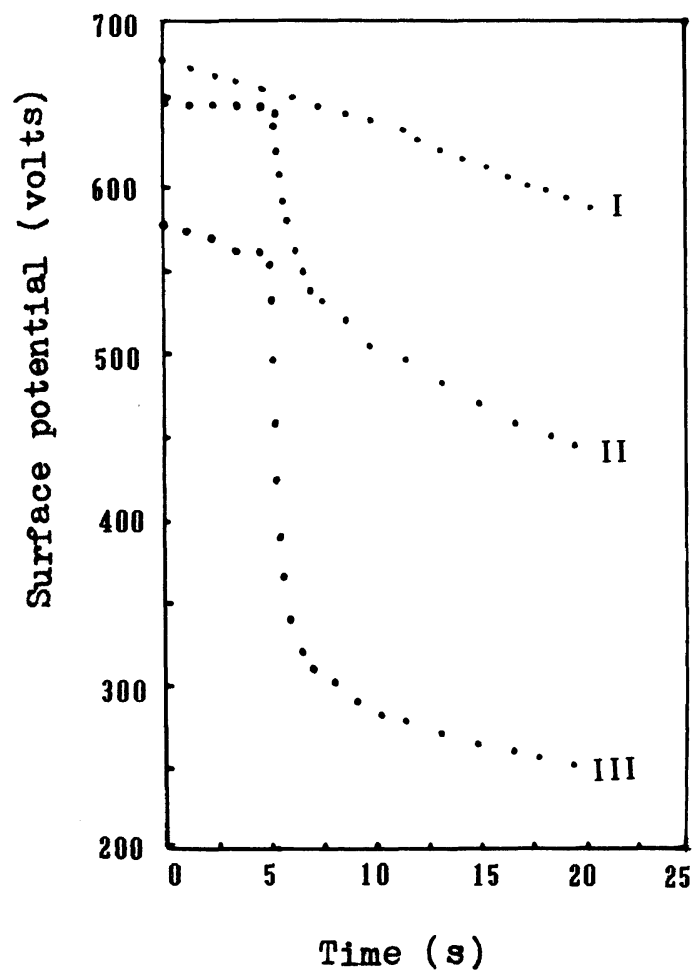

Figure 4. Dependence of the photosensitivity in the electron beam irradiated cis-PPA films on the preparation pressure. I: Original films (not compressed); II: Pressed at $300 \mathrm{~kg} \mathrm{~cm}^{-2}$; III; Pressed at $600 \mathrm{~kg} \mathrm{~cm}^{-2}$. Experimental conditions see in Figure 2. irradiated cis-PPA films was enhanced by increasing the compression pressure. A pressure of $600 \mathrm{~kg} \mathrm{~cm}^{-2}$ appeared to be ideal and optimum and possibly associated with the tight degree of the photosensitive samples.

The dependence of the photosensitivity on the storage time and temperature for cis-PPA films after irradiation by electron beams are given in Table II. The photosensitivity in irradiated PPA films deteriorated rapidly and returned to the level of unirradiated PPA films when the irradiated PPA films were heated in a nitrogen atmosphere over $50^{\circ} \mathrm{C}$ for more than one hour. Similarly, the photosensitivity in the irradiated PPA films deteriorated slowly with time when stored in air at room temperature. This is explained by the theory of "Equal Effect of Time and Temperature".

\section{Mechanism of High Photosensitivity in Irra- diated cis-PPA Films}

The electron beam irradiated cis-PPA films were characterized by using ESR, GPC, ${ }^{1} \mathrm{H}$ NMR and DTA in order to explain their photosensitivity improvement. The ESR, NMR, DTA spectra of the electron beam irradiated rare-earth cis-PPA have no remarkable change compared to the unirradiated ones, ${ }^{6-7}$ showing paramagnetism $\left(\sim 10^{15}\right.$ spins/g), a high cis-content ( $\sim 90 \%$ ), and good thermal stability (the order-disorder temperature: $\sim 175^{\circ} \mathrm{C}$ ). This shows that there was no noticeable structure change for cis-PPA during irradiation by electron beams in air atmosphere at room temperature. The GPC analysis shows the average molecular weight $\left(\bar{M}_{n}\right)$ irradiated cis-PPA dropped to $5 \times 10^{4}$, half of that of

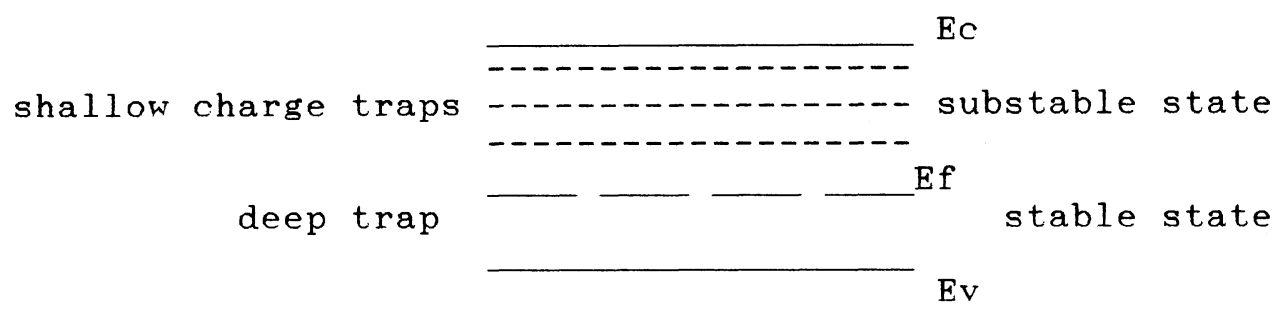

Figure 5. Energy band model for cis-PPA. 
unirradiated cis-PPA, but the molecular weight distribution (MWD) was unchange (MWD= 2.28). ${ }^{6}$ Thus, there was molecular degradation in cis-PPA during irradiation. According to the above results, a mechanism of high photosensitivity in the rare-earth cis-PPA films induced by electron beam irradiation may be suggested as follows: The cis-PPA film has unpaired electron (about $10^{15} \mathrm{spins} / \mathrm{g}$ ), as demonstrated by ESR. ${ }^{6}$ These unpaired electrons are in the stable states - deep traps under normal conditions. When PPA is irradiated by electron beams, many shallow charge traps can be produced. Because the gaps between these shallow charge trap states and conduction bands are so small that infrared light can make the charges jump to conduction bands. Thus, the charges in shallow traps produced from unpaired electrons by electron beams irradiation can absorb infrared light energy and jump to the conduction bands to produce high photosensitivity. Because the trapped charges produced by electron beam irradiation are unstable, they might gradually disappear with storage time or increasing storage temperature of the irradiated cis-PPA. This concept agrees with our experimental results. Further investigations is in progress.

Acknowledgment. This work was financed by the National Natural Science Foundation of China.

\section{REFERENCES}

1. E. T. Kang, P. Ehrlich, and W. A. Anderson, Mol. Cryst. Liq. Cryst., 106, 305 (1984).

2. E. T. Kang, P. Ehrlich, A. P. Bhatt, and W. A. Anderson, Macromolecules, 17, 1020 (1984).

3. E. T. Kang, A. P. Bhatt, E. Villareol, W. A. Anderson, and P. Ehrlich, Appl. Phys. Lett., 41, 1136 (1982).

4. M. J. Yang, J. Zhao, Z. Q. Shen, M. J. Zhang, and S. H. Lin, J. Polym. Sci., Polym. Chem. Ed., 27(11), 3829 (1989).

5. M. J. Yang, J. Zhao, and Z. Q. Shen, J. Chinese Rare Earth Soc., 5(2), 9 (1987).

6. J. Zhao, M. J. Yang, Y. M. Yuan, and Z. Q. Shen, J. Chinese Rare Earth Soc., 6(4), 17 (1988).

7. M. J. Yang, J. Zhao, and Z. Q. Shen, J. Chinese Rare Earth Soc., 5(3), 31 (1987). 